317 | juillet-septembre 1999

Numéro spécial : France-Allemagne. Interactions, références

\title{
Franc-maçonnerie et cosmopolitisme au siècle des Lumières
}

\section{Marc Belissa}

\section{(2) OpenEdition Journals}

\section{Édition électronique}

URL : https://journals.openedition.org/ahrf/939

DOI : $10.4000 /$ ahrf.939

ISSN : 1952-403X

\section{Éditeur :}

Armand Colin, Société des études robespierristes

Édition imprimée

Date de publication : 1 septembre 1999

Pagination : 563-564

ISSN : 0003-4436

Référence électronique

Marc Belissa, "Franc-maçonnerie et cosmopolitisme au siècle des Lumières », Annales historiques de la Révolution française [En ligne], 317 | juillet-septembre 1999, mis en ligne le 10 avril 2006, consulté le 22 avril 2022. URL : http://journals.openedition.org/ahrf/939 ; DOI : https://doi.org/10.4000/ahrf.939

Ce document a été généré automatiquement le 22 avril 2022.

Tous droits réservés 


\title{
Franc-maçonnerie et cosmopolitisme au siècle des Lumières
}

\author{
Marc Belissa
}

\section{RÉFÉRENCE}

Pierre-Yves BEAUREPAIRE, Franc-maçonnerie et cosmopolitisme au siècle des Lumières, Éditions maçonniques de France, collection « Encyclopédie maçonniques », Paris 1998, 128 pp., index des personnes, bibliographie sommaire.

1 Cet ouvrage de notre collèque de l'Université d'Artois P. Y. Beaurepaire présente dans cinq chapitres concis une synthèse de la problématique franc-maçonnerie/ cosmopolitisme. On retrouve là une partie des thèmes présents dans sa thèse " L'Autre et le Frère. L'Étranger et la Franc-maçonnerie en France au XviII ${ }^{e}$ siècle ", ouvrage qui a obtenu le prix Le Monde de la recherche universitaire, ainsi que le prix Blaise-Pascal. Le premier chapitre rappelle que le cosmopolitisme des maçons est «la clé de voûte de leur représentation du monde et des rapports qu'entretient la sphère maçonnique avec la sphère profane " (p. 12). Mais de quel « cosmopolitisme » s'agit-il ? d'une prise de position politiquement neutre? d'une forme spécifiquement maçonnique? ou d'une variante du cosmopolitisme des Lumières profanes? Dans le deuxième chapitre, l'auteur observe comment le «cosmos » maçonnique s'est articulé autour de réseaux particuliers fonctionnant comme des vecteurs des valeurs cosmopolites, mais aussi comme des points d'appui pour des stratégies d'intérêts plus prosaïques. Le troisième chapitre s'interroge sur les limites du cosmopolitisme maçonnique qui, tout comme les Lumières, a ses « zones d'ombre » et ses « exclus » (Juifs, Musulmans et Nègres). Enfin dans les deux derniers chapitres, on assiste à l'entrée du cosmopolitisme maçonnique dans le conflit révolutionnaire: comment la version "apolitique " défendue majoritairement par les Loges avant le début de la Révolution française réagit-elle face à l'offensive des "Lumières radicales" (l'auteur traite ici des tentatives de 
"récupération" par Bonneville et le Cercle social) puis à celle du "nationalisme naissant » qui émet des doutes sur la " prétention des frères à être des citoyens et des patriotes modèles » (p. 13)?

2 L'auteur nous montre tout d'abord que la profession de foi maçonnique est au cœur de la dialectique de l'universel et du particulier qui parcourt la pensée des Lumières. Les maçons proclament la hiérarchie des valeurs exposée par Fénelon, puis reprise par Ramsay, Montesquieu ou Mably: l'humanité est une Grande Famille dont les nations sont les membres, l'amour de la patrie doit être subordonné à celui de l'humanité. Mais cette " humanité » ne se limite-t-elle pas à la chrétienté européenne ? C'est là le point de vue de certains (la Stricte Observance notamment). On retrouve donc ici les éléments du débat des Lumières profanes que nous avions exposé dans notre propre thèse: le cosmopolitisme ne s'oppose pas au "patriotisme", mais il existe un « cosmopolitisme » européocentré (que l'on retrouve chez Leibniz par exemple).

3 Le cosmopolitisme maçonnique entend construire d'abord ses réseaux à l'échelle du continent: l'auteur nous montre comment ces réseaux s'organisent autour de nœuds de communication formant autant de «synapses " par lesquelles passe l'influx de la correspondance universelle. Mais le contrôle de ces réseaux est un enjeu d'importance et bientôt le Grand Orient - qui refuse « l'intrusion » britannique - cherche à se placer en position « d'interface » entre les réseaux nationaux et l'étranger, mettant ainsi en place les conditions de la constitution d'une maçonnerie «nationale». Deux conceptions différentes de la correspondance universelle s'opposent donc.

4 La maçonnerie se conçoit comme une élite "égalitaire», une communauté de Semblables soudée par des valeurs et des pratiques culturelles. C'est pourquoi certains frères du XVIII ${ }^{e}$ siècle entrent "dans une logique d'exclusion " (p. 59) en refusant une "altérité trop accusée ", une différence qui contribuerait à la dissolution de la communauté. Ainsi La Tierce considère les maçons comme les héritiers des Croisés en lutte contre l'infidèle, ainsi les Juifs - pourtant admis dans les loges en Angleterre au début du siècle - sont repoussés de la Parfaite Sincérité à Marseille ou de la Parfaite Amitié à Toulouse en 1764. Le problème est encore plus aigu en ce qui concerne les Nègres et les sang-mêlé dans les colonies européennes, les maçons des Antilles n'éprouvant aucun scrupule à reprendre les topoi racistes sur la tâche indélébile de la noirceur prédestinant à la servitude. Mais la maçonnerie n'est pas monolithique: les frères parisiens, par exemple, sont partie prenante de la Société des Amis des Noirs. Le cosmopolitisme "apolitique » défendu par les loges sous l'Ancien Régime est l'objet d'une attaque frontale pendant la Révolution. Nicolas de Bonneville tente sans succès de prendre le contrôle de la correspondance maçonnique en présentant le Cercle social comme un point de ralliement des réseaux existants. Lors du réveil de la maçonnerie sous le Consulat et l'Empire, le cosmopolitisme des Lumières est devenu suspect. Les frères doivent faire allégeance pour être reconnus par le pouvoir: ils multiplient alors les gestes symboliques pour montrer leur rejet de l'influence britannique et leur fidélité au régime napoléonien. En témoigne en 1810 la lettre de Waltersdorff de la Loge La réunion des Étrangers dans laquelle il explique pourquoi elle s'appellera désormais Respectable Loge Marie-Louise (pp. 114-115). À l'opposé de cette apostasie, Fichte tente de concilier le double engagement patriotique et cosmopolite, mais le cosmopolitisme maçonnique est touché de plein fouet par la montée du nationalisme. Cet ouvrage apporte sa pierre aux recherches récentes sur le cosmopolitisme et les théories politiques des Lumières, et à la réévaluation d'un concept trop souvent remisé par 
l'historiographie au rayon de l'histoire des utopies inoffensives. Malgré son volume réduit, ce livre éclaire de manière très convaincante la contribution spécifiquement maçonnique au débat des Lumières sur les relations entre les peuples. On regrettera néanmoins l'absence d'un petit lexique expliquant certaines expressions typiquement maçonniques, et donc parfois obscures pour le lecteur peu au fait de ce vocabulaire particulier. 